\title{
ONDE ESTÃO, O QUE ENSINAM E O QUE PRODUZEM OS MESTRADOS PROFISSIONAIS EM PLANEJAMENTO URBANO E REGIONAL
}

\author{
Rosélia Piquet $^{1}$ \\ Universidade Candido Mendes, Campos- RJ
}

\begin{abstract}
Resumo
O texto apresenta uma análise sobre os Mestrados Profissionais em Planejamento Urbano e Regional, baseada em dados oficiais da Coordenação de Pessoal de Nível Superior - Capes e disponíveis nos sites dos programas. Com base nesse material analisa os programas segundo sua localização, composição do corpo docente e disciplinas oferecidas. Indica que nessa área o papel dos mestrados profissionais vem se tornando relevante, em decorrência da crescente demanda por pessoal qualificado gerada pela retomada das questões relacionadas ao desenvolvimento regional, ao processo de descentralização administrativa e pelo próprio crescimento do país.
\end{abstract}

Palavras-Chave: mestrado profissional, planejamento urbano e regional e qualificação profissional.

\begin{abstract}
The text presents a panorama of the Professional Master's Programs in Urban and Regional Planning based on official data from Capes - Coordination for the Improvement of Higher Level Personnel of the Brazilian Ministry of Education - and on those available on the programs websites. Based on this material the text analyses these programs according to their location, the composition of the teacher staff and the subjects offered. In this area this modality of program is becoming relevant due to the increasing demand for qualified people generated by the resumption of issues related to regional development, by administrative decentralization process and by the country's growth.
\end{abstract}

Keywords: Professional Master's Program; Urban and Regional Planning; Professional Development.

\footnotetext{
${ }^{1}$ A autora agradece a colaboração da mestranda Mariana Pessoa pelo levantamento dos dados apresentados.
} 


\section{O sistema de pós-graduação no país - uma breve retrospectiva histórica}

A proposta de implantação de cursos de mestrado voltados para a qualificação profissional, designados Mestrados Profissionais, encontra-se presente no sistema de PósGraduação brasileiro desde a sua concepção original, ainda nos anos de 1950, quando começa a ser implantado o ensino de pós-graduação no Brasil. A proposta de montagem de um sistema capaz de corrigir as deficiências qualitativas e quantitativas na formação de quadros superiores emerge em um período de grande efervescência administrativa e institucional do país, pois se tratava, nos termos da época, de reaparelhar o Estado dotando-o de uma diversidade de órgãos e instrumentos que regulassem e permitissem a intervenção nos diferentes aspectos da vida nacional que atravessava então profundas alterações em seu sistema produtivo e em sua estrutura social.

Assim, em 11 de julho de 1951, pelo Decreto n. 29.741, da Presidência da República, é instituída uma Comissão para promover a Campanha Nacional de Aperfeiçoamento de Pessoal de Nivel Superior - CAPES, que surge simultaneamente a outros órgãos e agências que tiveram - e muitos deles ainda têm - importante presença na vida nacional, tais como a Comissão Nacional de Política Agrária, a Comissão Nacional de Alimentação, o Conselho Nacional de Pesquisas - CNPq, o Banco Nacional de Desenvolvimento Econômico - BNDE, a Companhia de Petróleo Brasileiro - Petrobras.

A CAPES é implantada como campanha porque, segundo o diagnóstico do então Ministro da Educação, Simões Filho, para corrigir a

"deformidade congênita de nossa formação profissional, não seria adequada mais uma lei ou mais uma repartição pública, mas sim uma campanha, algo vivo que despertasse o interesse e a colaboração de todos". ${ }^{2}$

Os dados do Censo de 1950 de fato tornaram evidentes grandes mudanças quando comparados aos de 1940, revelando uma acentuada transferência da mão de obra para os setores secundário e terciário da economia e um acelerado aumento da migração populacional do Nordeste para o Centro-Sul. O contingente de profissionais de nível superior correspondia a $0,7 \%$ da massa da população economicamente ativa, atingindo em valores absolutos 132.035 profissionais. Ainda segundo Simões Filho,

"urgia estimular a expansão do Ensino Superior e fazê-lo segundo novos paradigmas de qualidade, pois não se dispunha de gente capacitada para os postos em que se exigem conhecimento e técnicas, indispensáveis ao tipo atual de sociedade, eminentemente industrial e técnico" e, ainda,

"o primado das letras sobre as ciências, que foi um dos males de nossa formação cultural, precisa ser corrigido nas suas consequências atuais, sendo necessário promover a formação de especialistas como economistas, técnicos em finanças, estatísticos, pesquisadores sociais visando a obtenção de tripulações para novas unidades, não só de empreendimentos governamentais, como também da iniciativa privada."

\footnotetext{
${ }^{2}$ Entrevista concedida pelo Ministro da Educação Simões Filho, no dia seguinte ao decreto presidencial criando a Comissão. Apud Rogério de Andrade Córdova, Boletim InfoCapes, comemorativo dos 45 anos. Capes, 1997.

3 Ibid.
}

RBPD - Revista Brasileira de Planejamento e Desenvolvimento, v. 1 , n. 1, p. 1-12, jul./dez. 2012 
Em seu início, a CAPES foi estruturada com apenas dois programas: o Programa Universitário visando o desenvolvimento das universidades e institutos de ensino superior e o Programa de Quadros Técnicos e Científicos, para atender à demanda de pessoal de nível superior por parte dos meios profissionais e culturais do país.

Pelo exposto, vê-se que em sua origem, a capacitação de quadros profissionais mereceu a mesma atenção que a formação de quadros universitários. É nas décadas de 1960 e, principalmente na de 1970, que essa orientação se altera e o Governo brasileiro passa a investir maciçamente na formação de profissionais de maior poder multiplicador - os professores do ensino superior - para garantir a formação dos quadros de docentes e pesquisadores, essenciais para a expansão do próprio sistema e para a promoção da pesquisa científica e tecnológica no País.

A partir de então, o crescimento da pós-graduação no Brasil baseia-se em cursos de mestrado que se caracterizam predominantemente como o primeiro degrau para a qualificação acadêmico-científica necessária à carreira universitária, caracterizando-se também como etapa preliminar na obtenção do grau de Doutor.

Contudo, passaram a surgir iniciativas de oferta de mestrados dirigidos à formação de profissionais, muitas vezes em resposta direta a demandas de agências e empresas, interessadas na qualificação de seus quadros e, a partir da década de 1990, fatores relacionados com as profundas transformações observadas - globalização da economia, modernização dos sistemas de produção, aumento da competitividade internacional determinaram uma crescente demanda por profissionais com perfil de qualificação especializada e não voltada para a pesquisa acadêmica. Assim, e ainda segundo a CAPES em documento de 1995, a qualificação acadêmico-científica, ao contrário do que se pensava na década de 1960,

"não é mais suficiente para também assegurar a formação de pessoal de alta qualificação para atuar nas áreas profissionais, nos institutos tecnológicos e nos laboratórios industriais." 4

Desse modo, observa-se que a proposta de implantação de cursos de mestrado voltados para a qualificação profissional, designados mestrados profissionais, que se efetiva em 1998, apenas ativou o que estava latente no sistema desde sua concepção original. Entretanto, em lugar de uma aceitação tranquila, a implantação dessa modalidade de curso contou desde logo com uma significativa rejeição da comunidade acadêmica.

Mas por que a polêmica em relação aos mestrados profissionais?

Durante muito tempo, e de certa forma até os dias de hoje, o grau de mestre foi o título mais presente no cenário acadêmico brasileiro, e a maioria dos cursos eram e continuam sendo de mestrado. A associação exagerada dos cursos de mestrado com o conhecimento e o mundo da academia, que ocorreu quando da implantação desses cursos no país, tornou problemática sua abertura para o mundo profissional.

Qual seria, então, a especificidade do Mestrado Profissional? A que projeto institucional ele pode ser associado? Sem pretender responder de forma conclusiva à questão de natureza tão complexa, a seguir são apresentados argumentos dessa polêmica.

De início os mestrados profissionais foram vistos como cursos de especialização com dissertação, que teriam como objetivo último aumentar o valor de mercado dos cursos de especialização. Contudo, há profundas diferenças entre os mesmos. Os cursos de

\footnotetext{
${ }^{4}$ Resolução n. 1/95 do Conselho Superior da Capes, com base no documento "Programa de Flexibilização do Modelo de Pós-Graduação, senso estrito, em nível de mestrado".
} 
especialização possibilitam a verticalização do conhecimento em uma subárea específica, visando uma qualificação circunscrita, sendo seu objetivo o de ensinar técnicas. Já os mestrados profissionais devem ser vistos como cursos que a partir de uma visão horizontal do saber consolidado em um campo disciplinar - com as evidentes relações interdisciplinares -, busca enfrentar problemas concretos, utilizando de forma direcionada o conhecimento existente para equacionar tais problemas. Seu objeto é a aplicação, em um campo profissional definido, de conhecimentos e métodos científicos atualizados.

O mestrado tradicional, hoje denominado "acadêmico", tem um objetivo consensual: buscar expor o mestrando à literatura científica da área, treiná-lo em atividades de pesquisa, buscando qualificá-lo para o magistério superior, sendo por isso geralmente seguido do doutorado. Das dissertações apresentadas não é esperado que produzam conhecimento, mas sim que sejam um exercício estruturado de aprendizagem com início, meio e fim incluindo, entre os objetivos quanto à formação dos mestrandos, o aprender a receber críticas, o respeito à ética da investigação e a sinceridade da dúvida.

Já no mestrado profissional, além dos objetivos quanto à formação dos mestrandos indicados anteriormente, seus trabalhos de conclusão geralmente são voltados à interpretação da prática, ao delineamento de linhas de ação, com base no conhecimento de conceitos e teorias e na discussão de ideias, apresentados sob a forma de dissertações ou outra mais adequada à área a que pertença. O conhecimento adquirido e os trabalhos de conclusão permitem uma oportunidade de maior aproximação entre as pesquisas conduzidas pelas Universidades e as demandas existentes no campo social e profissional, proporcionando assim um encurtamento dos prazos entre a investigação e a sua aplicabilidade.

Seu objetivo é encontrar o caminho da resposta a uma pergunta específica proposta pela área profissional ou identificada pela Universidade, como algo que deva ser investigado naquela área. Segundo Mattos,

"se a academia se supõe credenciada, pela natureza do que produz, a falar ao mundo da empresa, do planejamento e da produção, é forçoso que aceite discutir formas alternativas de produzir conhecimento crítico com finalidades práticas que não o atendimento de suas próprias preocupações e polêmicas internas, ou a manutenção de suas tradições e instituições."

Assim entendido,

"o mestrado profissional configura a viabilidade da Universidade atuar
de forma pró-ativa, usando os seus recursos para identificar áreas,
problemas e impasses que se beneficiariam, e muito, do contato com o
que é investigado na sua rotina." (GAZZOLA, 2003)

É importante frisar que as duas modalidades de curso - o mestrado acadêmico e o profissional - estão sujeitas à mesma legislação que rege a autorização, o reconhecimento e a renovação de reconhecimento de cursos pela Capes e devem apresentar padrões de qualidade equivalentes. O que deve ser perseguido é a garantia da qualidade e, neste sentido, tanto os mestrados acadêmicos quanto os profissionais, embora cumprindo propostas diferenciadas de habilitação, devem assegurar formação de igual nível e qualidade. ${ }^{5}$

\footnotetext{
${ }^{5}$ Portaria Capes n. 080, de 16 de dezembro de 1998, que dispõe sobre o reconhecimento dos mestrados profissionais, e publicada no Diário Oficial de 11/01/99, seção I, pág. 14. E ainda o documento: A necessidade de desenvolvimento da pós-graduação profissional e o ajustamento do Sistema de Avaliação às características desse segmento. Boletim da Capes de 13/12/2001.
} 


\section{O ensino do Planejamento Urbano e Regional no Brasil}

No caso latino-americano, a difusão e auge do planejamento alcançaram sua máxima expressão na década de 1960 chegando mesmo em certos âmbitos tecnocráticos e acadêmicos a se observar uma clara tendência a idealizar a capacidade do planejamento como instrumento capaz de promover o desenvolvimento econômico e social. À medida que as idéias relacionadas com o planejamento foram ganhando impulso, os diagnósticos começaram a destacar a importância dos problemas regionais e urbanos e a recomendar a necessidade de incorporar medidas capazes de enfrentá-los. Segundo essa concepção o Estado é visto como agente político e econômico capaz de conduzir projetos de desenvolvimento que resultassem, não apenas na expansão do produto e do emprego, mas que também buscassem superar desequilíbrios espaciais. O processo de planejamento foi durante esse tempo considerado uma técnica de aplicação de políticas.

$\mathrm{Na}$ medida em que a atividade ganhava corpo foi simultaneamente percebida a carência de pessoal qualificado e a Organização dos Estados Americanos - OEA, a Comissão Econômica para a América Latina - CEPAL e o Instituto Latino-americano e do Caribe de Planificação Econômica e Social - ILPES se constituíram nas instituições que realizaram esforços na formação de recursos humanos para apoiar e guiar os trabalhos de elaboração dos planos. Embora no início os programas de capacitação tenham sido assumidos por essas agências e estivessem dirigidos aos funcionários públicos envolvidos nas tarefas do planejamento, logo as universidades tomaram a si a tarefa quando então começam a surgir os programas de pós-graduação em planejamento urbano e regional na América Latina.

No Brasil, é nos anos 1970 que o planejamento governamental assume um elevado grau de institucionalidade, durante o auge dos governos militares, o que lhe confere caráter centralizador. É quando também a capacitação de pessoal na área começa a ganhar impulso e são então lançados os primeiros cursos de mestrado sobre planejamento urbano e regional na Universidade Federal do Rio Grande do Sul (1970), na Universidade Federal do Rio de Janeiro (1972), na Universidade Federal de Pernambuco (1975) e Universidade de Brasília. A Universidade Federal de Minas Gerais já havia criado em 1967 o Centro de Desenvolvimento e Planejamento Regional - Cedeplar, com a finalidade de abrigar um programa de pesquisa e ensino de pós-graduação na área da Economia Regional. Era de tal ordem a importância atribuída à formação de quadros para atuação no sistema de planejamento que a primeira turma do curso da UFRJ, então sob a responsabilidade da Coordenação dos Programas de Pós-graduação em Engenharia - COPPE, é destinada a técnicos do Banco Nacional de Habitação - BNH, do Serviço Federal de Habitação e Urbanismo - SERFHAU e de órgãos do governo federal envolvidos com o planejamento urbano ou regional.

Ao longo da década de 1980 as novas tendências na dinâmica socioeconômica mundial, configurando um novo cenário com significativas diferenças em relação ao período do pós-guerra, põem em cheque o planejamento, que em nosso país passa a ser recusado, posto que identificado com o autoritarismo, com o "olhar do burocrata". Assim, com o enfraquecimento do Estado, o planejamento cai em descrédito e os programas de pósgraduação, montados para a formação de pessoal na área, gradualmente se transformam de fato em programas de estudos urbanos e regionais, sendo sintomático que no período de quase 20 anos (entre 1975 e 1993) nenhum novo curso tenha sido proposto na área.

A partir dos anos 1990, a redução da face produtiva do Estado e a tendência à adoção de políticas descentralizadoras tornam as instâncias subnacionais de governo atores mais relevantes na atuação do setor público. Neste cenário, caracterizado por diferentes dinâmicas 
sociais e de distribuição do poder entre atores sociais, a gestão e as políticas públicas tornamse diferentes daquelas que imperavam na época do planejamento centralizado, o que impõe desafios diversos aos programas de formação de recursos humanos. Contudo, é só a partir dos anos 2000, quando o país dá sinais de recuperação econômica com a retomada de vultosos investimentos em projetos estruturantes, que se volta a falar na premência de se pensar o longo prazo - o que implica na retomada do planejamento - e quando então novos cursos são propostos. Este seria também o momento ideal para se repensar o conteúdo dos programas formativos, de se redefinir o que neles se ensina e de se propor novos formatos de cursos mais voltados à análise das realidades regionais e locais. É então quando surgem as primeiras propostas de Mestrados Profissionais na área, conforme pode ser observado no Quadro 1.

Quadro 1 - Mestrados Profissionais recomendados pela CAPES na área de Planejamento Urbano e Regional - 2012

\begin{tabular}{|c|c|c|c|c|c|c|c|c|}
\hline & Programa & Instituição & Região & Cidade & Dependência & Nível & Início & Conceito \\
\hline 1 & $\begin{array}{l}\text { Planejamento Regional e } \\
\text { Gestão da Cidade }\end{array}$ & $\begin{array}{l}\text { Universidade Candido } \\
\text { Mendes (UCAM) }\end{array}$ & Sudeste & Campos, RJ & Particular & M & 2001 & 4 \\
\hline 2 & Desenvolvimento Regional & $\begin{array}{l}\text { Faculdade Alves Faria } \\
\text { (ALFA) }\end{array}$ & $\begin{array}{l}\text { Centro } \\
\text { Oeste }\end{array}$ & Goiânia, GO & Particular & M & 2007 & 3 \\
\hline 3 & Planejamento Ambiental & $\begin{array}{l}\text { Universidade Católica de } \\
\text { Salvador }\end{array}$ & Nordeste & Salvador, BA & Particular & M & 2007 & 3 \\
\hline 4 & $\begin{array}{l}\text { Planejamento Territorial e } \\
\text { Desenvolvimento } \\
\text { Socioambiental }\end{array}$ & $\begin{array}{l}\text { Universidade do Estado } \\
\text { de Santa Catarina } \\
\text { (UDESC) }\end{array}$ & Sul & $\begin{array}{l}\text { Florianópolis, } \\
\text { SC }\end{array}$ & Estadual & M & 2007 & 3 \\
\hline 5 & $\begin{array}{l}\text { Políticas Sociais e Dinâmicas } \\
\text { Regionais }\end{array}$ & $\begin{array}{l}\text { Universidade Comunitária } \\
\text { da Região de Chapecó } \\
\text { (UNOCHAPECÓ) }\end{array}$ & Sul & Chapecó, SC & Particular & M & 2010 & 3 \\
\hline 6 & $\begin{array}{l}\text { Planejamento e Governança } \\
\text { Pública }\end{array}$ & $\begin{array}{l}\text { Universidade Tecnológica } \\
\text { Federal do Paraná } \\
\text { (UTFPR) }\end{array}$ & Sul & Curitiba, PR & Federal & M & 2010 & 3 \\
\hline 7 & Desenvolvimento Regional & $\begin{array}{l}\text { Instituto de Ensino } \\
\text { Superior e Pesquisa } \\
\text { (INESP) }\end{array}$ & Sudeste & $\begin{array}{l}\text { Divinópolis, } \\
\text { MG }\end{array}$ & Particular & M & 2011 & 3 \\
\hline
\end{tabular}

Fonte: Coordenação de Aperfeiçoamento de Pessoal de Nível Superior (CAPES). Disponível em:

http://www.capes.gov.br/cursos-recomendados

Levantamento de dados por Mariana Pessoa, mestrando do Programa de Planejamento Regional e Gestão de Cidades.

\section{Os Mestrados Profissionais em Planejamento Urbano e Regional}

Se em seus primórdios os mestrados da área já poderiam ser vistos como cursos predominantemente voltados à prática profissional e não à reprodução da estrutura acadêmica, hoje essa direção se afirma mais ainda. Sem dúvida o Planejamento Urbano e Regional não se constitui em campo de conhecimento específico, mas sim em área de aplicação de conhecimentos. O enfrentamento teórico e político das questões dos anos 2000 requer avançar nas análises territoriais com pesquisas que busquem identificar a lógica de funcionamento dos vários circuitos de valorização do capital, em seus vínculos com as condições de vida da população. Para que seja reconhecida a dimensão deste desafio, convém destacar que, no país, como afirma Brandão, 
"nunca as diversidades produtivas, sociais, culturais, espaciais (regionais, urbanas e rurais) foram usadas no sentido positivo. Foram tratadas sempre como desequilíbrios, assimetrias $e$ problemas".

O autor alerta, portanto, para a necessidade de que sejam reconhecidas as potencialidades existentes na diversidade, o que implica na articulação entre processos econômicos transescalares e no reconhecimento da história relativamente autônoma, de regiões e lugares. Questionar os interesses constituídos nos mais de cinco mil municípios, distribuídos numa grande variedade de contextos regionais, e estudar o papel exercido pelo agronegócio, pelo capital imobiliário e industrial, pelo capital financeiro e, pelas organizações políticas e sociais nas mudanças territoriais são, sem dúvida, tarefas do presente.

A descentralização administrativa trouxe novas questões relacionadas à procura de pessoal qualificado, sendo que a consolidação desse processo passou a exigir um melhor aparelhamento das administrações públicas locais, com o consequente aumento da demanda por profissionais para atuar em prefeituras e órgãos públicos em geral. Embora o planejamento, neste âmbito, se limite a ser em geral um esforço de coordenação administrativa, não atingindo o estágio da produção de efetivas mudanças estruturais, a ampliação de conhecimento sobre os processos econômicos, socioespaciais e culturais requer ação qualificada do corpo técnico envolvido nas tarefas administrativas. A carência de melhores e mais numerosas pesquisas sobre a diversidade regional e urbana brasileira vem encontrando resposta na ampliação da oferta de cursos na área, em conexão, inclusive, com a nova distribuição espacial dos investimentos públicos e privados no território nacional.

Até o presente, contudo, o país enfrenta carência de pessoal qualificado em todos os níveis de ensino e embora se tenha conseguido que a quase totalidade das crianças entre 6 e 14 anos esteja matriculada na escola, a formação de profissionais, de nível técnico ou superior em quantidade e qualificação suficientes para atender ao mercado de trabalho são ainda insuficientes. Mesmo aqueles que conseguem obter o diploma universitário nem sempre estão dentro dos padrões que as empresas e a administração pública precisam, o que tem provocado uma demanda diferenciada no ensino de pós-graduação stritu sensu brasileiro: a busca por melhor qualificação para o mercado de trabalho e não mais para a entrada na carreira universitária. É a esse tipo de demanda que se voltam os Mestrados Profissionais.

Essa modalidade é ainda pouco representativa na composição dos cursos da pósgraduação brasileira sendo ainda atrelados às concepções dos mestrados acadêmicos, principalmente pelo fato de que algumas áreas ainda não estabeleceram critérios diferenciados para sua avaliação. Tal fato inibe a apresentação de propostas mais específicas e inovadoras pelo receio de sua não aprovação pelos comitês avaliadores, onde predominam representantes dos programas de mestrados acadêmicos e doutorados. Esta circunstância, segundo Moura Castro.

\section{"condena os mestrados profissionais a uma mímica da vida acadêmica e da pesquisa 'científica' totalmente inapropriada para sua índole profissional."}

A análise a seguir desenvolvida é baseada nos registros da Capes referentes aos cursos da área de Planejamento Urbano e Regional e Demografia assim como nas informações dos próprios Programas divulgadas na internet. A subárea de Demografia não tem até o momento nenhum curso na modalidade analisada, razão pela qual não é mencionada no texto. 
Pelos dados do Quadro 1, vê-se que todos os mestrados profissionais foram propostos já nos anos 2000, sendo um credenciado ainda em 2001 e os demais somente a partir de 2007. Um dos traços que indica o comportamento tímido quanto a propostas inovadoras, como referido anteriormente, é o fato de que embora as regras gerais da Capes permitam e até mesmo recomendem a contratação de professores que embora não sendo doutores possuam um saber reconhecido na área, todo o corpo docente dos programas é constituído exclusivamente por doutores. Nesse mesmo sentido, todos exigem como trabalho de conclusão a elaboração de uma dissertação.

As universidades particulares predominam e oferecem 5 desses cursos de um total de 7, o que define uma composição de dependência administrativa diversa em relação aos programas acadêmicos onde as universidades particulares têm uma presença modesta, com apenas 7 dos 30 cursos existentes.

Um traço marcante dos mestrados profissionais é que apenas um leva no título a palavra "urbano". Contudo esse é um traço comum tanto nos mestrados profissionais quanto nos acadêmicos, sendo relacionado ao período de sua criação, pois nos cursos propostos após 2000 a referência ao urbano é quase inexistente, ocorrendo em apenas dois. Tal fato indica uma mudança de foco da área, o que provavelmente corresponde ao reconhecimento dos desafios específicos quanto à necessidade de melhor se conhecer as regiões não hegemônicas do país e, também, à nova dinâmica espacial da economia brasileira, pois as maiores regiões metropolitanas vêm perdendo posição relativa frente às cidades de porte médio e às metrópoles de segundo grau.

Cabe registrar que nos cursos implantados nos anos 1970, a presença de disciplinas da área de arquitetura e urbanismo era marcante e todos tinham não só no título a referência ao urbano como também a composição curricular era voltada ao estudo e ao planejamento metropolitano. As questões regionais, quando tratadas o eram sob a perspectiva das desigualdades entre as macrorregiões brasileiras.

\section{(i) Onde estão localizados}

Os cursos estão localizados em cidades de porte médio no interior do país ou em metrópoles de segundo grau, conforme Tabela 1. A participação da população com grau superior, um dos indicadores que permite estimar o nível de capacitação de um lugar, é bastante diferenciada entre as cidades que abrigam esses cursos. Enquanto as capitais apresentam um bom nível, onde se destaca Florianópolis e Salvador fica como exceção, as cidades de porte médio têm um percentual relativamente baixo de população com nível superior completo. Contudo, vê-se o quanto o país avançou na formação universitária quando se compara os dados do presente aos níveis da década de 1940/50 referidos no item 1 desse texto.

A Tabela 1 também indica que à exceção da Região Norte as demais macrorregiões brasileiras têm cursos nessa modalidade, cabendo destaque para a Região Sul, o que provavelmente reflete a grande ênfase que vem sendo dada nos Estados de Santa Catarina e Paraná ao planejamento estadual.

Tabela 1 - Mestrados Profissionais e a população das cidades de localização

\begin{tabular}{|c|c|c|c|c|c|c|}
\hline Programa & Instituição & Região & Cidade & População & $\begin{array}{c}\text { População } \\
\text { com nível } \\
\text { superior } \\
\text { completo } \\
\text { (b) }\end{array}$ & (b)/(a) \\
\hline
\end{tabular}


$\boldsymbol{R} \boldsymbol{B} \boldsymbol{P} \boldsymbol{D}$ ONDE ESTÃo, O QUe ensinAM e O QUe PROdUZEM OS ...

\begin{tabular}{|c|c|c|c|c|c|c|c|}
\hline 1 & $\begin{array}{l}\text { Planejamento } \\
\text { Regional e Gestão da } \\
\text { Cidade }\end{array}$ & $\begin{array}{l}\text { Universidade } \\
\text { Candido Mendes } \\
\text { (UCAM) }\end{array}$ & Sudeste & Campos, RJ & 463.731 & 31.658 & 6,8 \\
\hline 2 & $\begin{array}{l}\text { Desenvolvimento } \\
\text { Regional }\end{array}$ & $\begin{array}{l}\text { Faculdades Alves } \\
\text { Faria (ALFA) }\end{array}$ & $\begin{array}{l}\text { Centro } \\
\text { Oeste }\end{array}$ & Goiânia, GO & 1.302 .001 & 177.697 & 13,6 \\
\hline 3 & $\begin{array}{l}\text { Planejamento } \\
\text { Ambiental }\end{array}$ & $\begin{array}{l}\text { Universidade } \\
\text { Católica de } \\
\text { Salvador (UCSAL) } \\
\end{array}$ & Nordeste & Salvador, BA & 2.675 .656 & 255.606 & 9,6 \\
\hline 4 & $\begin{array}{l}\text { Planejamento } \\
\text { Territorial e } \\
\text { Desenvolvimento } \\
\text { Sócio-Ambiental }\end{array}$ & $\begin{array}{l}\text { Universidade do } \\
\text { Estado de Santa } \\
\text { Catarina (UDESC) }\end{array}$ & Sul & $\begin{array}{l}\text { Florianópolis, } \\
\text { SC }\end{array}$ & 421.240 & 90.436 & 21,5 \\
\hline 5 & $\begin{array}{l}\text { Políticas Sociais e } \\
\text { Dinâmicas Regionais }\end{array}$ & $\begin{array}{l}\text { Universidade } \\
\text { Comunitária da } \\
\text { Região de Chapecó } \\
\text { (UNOCHAPECÓ) }\end{array}$ & Sul & Chapecó, SC & 183.530 & 16.402 & 8,9 \\
\hline 6 & $\begin{array}{l}\text { Planejamento e } \\
\text { Governança Pública }\end{array}$ & $\begin{array}{l}\text { Universidade } \\
\text { Tecnológica } \\
\text { Federal do Paraná } \\
\text { (UTFPR) }\end{array}$ & Sul & Curitiba, PR & 1.751 .907 & 307.175 & 17,5 \\
\hline 7 & $\begin{array}{l}\text { Desenvolvimento } \\
\text { Regional }\end{array}$ & $\begin{array}{l}\text { Instituto de Ensino } \\
\text { Superior e } \\
\text { Pesquisa (INESP) }\end{array}$ & Sudeste & $\begin{array}{l}\text { Divinópolis, } \\
\text { MG }\end{array}$ & 213.016 & 18.494 & 8,7 \\
\hline
\end{tabular}

Fonte: Coordenação de Aperfeiçoamento de Pessoal de Nível Superior (CAPES).

Disponível em: http://www.capes.gov.br/cursos-recomendados

Levantamento dos dados por Mariana Pessoa, mestranda do Programa em Planejamento Regional e Gestão de

Cidades.

\section{(ii) Formação do corpo docente}

A formação dos docentes, cujos dados se encontram sintetizados na Tabela 2 se caracteriza não só por apresentar grande diversidade disciplinar, como também pelo fato de que cada docente obteve seus títulos de graduação, mestrado e doutorado em cursos de natureza diversa. Esse é um dado que merece registro, pois no momento a diretoria da Capes vem promovendo debates com o intuito de discutir a importância da interdisciplinaridade e da transdisciplinaridade na formação acadêmica para o mundo do século XXI.

A área de Planejamento Urbano e Regional ainda não realimenta a formação de seus quadros docentes, uma vez que apenas dois docentes de um total de 64 são egressos da própria área. Conforme pode ser observado na Tabela 2 as áreas que predominam na formação docente são: Administração de Empresas como a graduação de maior representatividade, e Engenharia da Produção quanto aos graus de mestre e doutor.

Tabela 2 - Formação de Docentes

\begin{tabular}{|l|c|c|c|}
\hline \multirow{2}{*}{ Nome do Curso } & \multicolumn{3}{|c|}{ Nível } \\
\cline { 2 - 4 } & Graduação & Mestrado & Doutorado \\
\hline Administração de Empresas & 11 & 8 & 5 \\
\hline Economia & 10 & 2 & 6 \\
\hline
\end{tabular}


$\boldsymbol{R} \boldsymbol{B} \boldsymbol{P} \boldsymbol{D}$ ONDE ESTÃo, O QUe ensinAM e O QUe PROdUZEM OS ...

\begin{tabular}{|l|c|c|c|} 
Engenharia da Produção & 3 & 9 & 11 \\
\hline Geografia & 7 & 5 & 8 \\
\hline Ciências Sociais & 6 & 2 & 2 \\
\hline Planejamento Urbano e Regional & - & 3 & 1 \\
\hline Arquitetura e Urbanismo & 3 & 3 & 2 \\
\hline Direito & 3 & 1 & 19 \\
\hline Demografia & - & 21 & 1 \\
\hline Outros cursos & & & 2 \\
\hline
\end{tabular}

Dados obtidos nos sites dos Programas.

\section{(iii) O que ensinam}

A análise da oferta de disciplinas do conjunto dos mestrados profissionais indica claramente que são cursos voltados à análise de suas próprias regiões, sendo que apenas em um deles é ministrada disciplina sobre o desenvolvimento brasileiro. Em contra partida são oferecidas 16 disciplinas de Instrumentos de Análise Regional. Surpreende a baixa oferta de disciplinas sobre as questões das administrações locais, pois em apenas um Programa essa disciplina é obrigatória e em três outros consta como eletiva.

Embora a oferta de disciplinas teóricas, 18 no total dos Programas, possa ser considerada elevada, apenas cinco são elencadas como obrigatórias. Coerentemente com os títulos dos Programas, apenas dois registram disciplinas especificamente voltadas para a análise do fenômeno urbano. As disciplinas de caráter metodológico geral constam da estrutura curricular de seis Programas, enquanto que as voltadas à orientação para pesquisa são em número marcadamente superior. Passam a fazer parte dos currículos regulares, disciplinas quanto ao agronegócio, ao meio ambiente, à biodiversidade e à questão energética.

\section{(iv) O que produzem}

As dissertações são o mais importante produto de um programa de mestrado. No caso específico sob análise apenas um desses cursos apresenta um número significativo de dissertações defendidas, pois os demais, por serem relativamente novos, apresentam resultados ainda modestos. Entretanto, por sua própria proposição original os programas de mestrados profissionais têm um papel a cumprir perante as regiões em que se localizam que os diferencia dos mestrados acadêmicos. Deles, outras modalidades de "produtos" poderiam ser esperados, tais como a divulgação de boletins sobre problemas que afetem a região; série de textos voltados à análise regional, ou alguma outra forma de tornar pública a produção de seus docentes e discentes. Ou seja, neste item a indagação levantada foi: os cursos dessa modalidade já vêm buscando organizar veículos próprios para a divulgação de sua produção acadêmica como forma de estreitar os vínculos com as regiões e cidades onde operam?

\footnotetext{
${ }^{6}$ Diante da grande diversidade das demais formações (com representações de um a dois professores)". Optou-se por agrupá-las em "outros cursos" sendo exemplos: Sociologia, Antropologia, Serviços sociais, História, Agronomia, Ciências Biológicas, Biologia, Meio Ambiente, Psicologia, Enfermagem e Outros.
} 
O que foi apurado é que apenas um deles vem desde 2003 publicando um boletim trimestral com objetivo de difundir e promover o debate sobre as rendas petrolíferas e mantém ainda em operação um banco de dados que disponibiliza informações sobre a distribuição dos royalties e participação especiais, uma das mais importantes questões que afetam a região em que o Programa se localiza.

Dada à reconhecida dificuldade de elaboração e manutenção de periódicos de qualidade, os coordenadores, em fevereiro de 2012, tomaram a decisão de propor a implantação de uma revista sob a responsabilidade do coletivo dos programas e que fosse voltada à difusão do conhecimento científico quanto ao planejamento e ao desenvolvimento econômico e social em suas dimensões regionais e urbanas. Essa proposta está em processo de concretização com a publicação do primeiro número da Revista Brasileira de Planejamento e Desenvolvimento, cujo primeiro número vem a público em dezembro de 2012. 


\section{Concluindo}

São claras as transformações pelas quais a área passou em termos de composição curricular, campos de atuação, formação docente e localização. Enquanto os primeiros programas da área são voltados ao planejamento urbano-metropolitano, na virada do século esse padrão irá mudar. Os novos cursos trazem a temática do desenvolvimento regional, agora tratado não mais sob a perspectiva dos desequilíbrios entre as macrorregiões brasileiras (Norte, Nordeste, Sudeste, Sul e Centro-Oeste), mas sim focado em regiões delimitadas do interior do país ou sobre a problemática das regiões metropolitanas de segundo nível.

Nesses cursos, de orientação regional mais nítida, observa-se a interlocução mais próxima com áreas de conhecimento tais como Administração de Empresas, Engenharia da Produção, Economia, Geografia, Ciências Agrárias, Meio Ambiente. O desafio de aceitar essa variedade de abordagens disciplinares e metodológicas é reconhecer e tratar tais diferenças sem gerar perdas teóricas ou cair em casuísmos. Esse desafio inclui, também, a superação de generalizações que pouco avançam no conhecimento da diversidade que caracteriza o país.

Sem dúvida, cada vez mais, a sociedade brasileira requer ser melhor conhecida, o que dependerá da promoção de estudos, pesquisas e debates, entre especialistas e atores políticos, centrados na construção de um futuro socialmente mais justo e territorialmente menos desigual. Na construção desse futuro, os mestrados profissionais muito terão a contribuir.

\section{Referências Bibliográficas}

BRANDÃO, Antônio Carlos. A Busca da Utopia do Planejamento Regional. Revista Paranaense de Desenvolvimento, Curitiba, n.120, p.11-31, jan./jun. 2011.

CAPES. A necessidade de desenvolvimento da pós-graduação profissional e o ajustamento do Sistema de Avaliação às características desse segmento. Boletim da Capes, dez. 2001.

CASTRO, Cláudio Moura. A hora do mestrado profissional. In: Revista Brasileira de Pósgraduação, v.2 n.4. 2005. p. 16-23.

CÓRDOVA, Rogério de Andrade. A brisa dos anos cinqüenta: a origem da Capes. Apud Boletim Infocapes, comemorativo dos 45 anos, 1997.

GAZZOLA, Ana Lúcia Almeida. Considerações iniciais sobre os conceitos de Mestrado Profissional e de Especialização. Belo Horizonte: UFMG, 2003 (mimeo).

MATTOS, Pedro Lincoln. Dissertações Não-Acadêmicas em Mestrados Profissionais: isso é possível? Revista de Administração Contemporânea, Curitiba: ANPAD, v.1, n.2, p.153-173, mai/ago, 1997. 